\title{
CNS aspergillosis in organ transplantation: a clinicopathological study
}

Julian Torre-Cisneros, Oscar L Lopez, Shimon Kusne, A Julio Martinez, Thomas E Starzl, Richard L Simmons, Maureen Martin

\begin{abstract}
The clinical characteristics and neuropathological findings of 22 organ transplant recipients with CNS aspergillosis were reviewed. Thirteen patients had liver, six kidney, two heart and one had cluster transplants. The most frequent neurological symptoms were alteration of mental status (86\%), seizures (41\%) and focal neurological deficits (32\%). Meningeal signs were less common (19\%). Aspergillus spp invasion of the blood vessels with subsequent ischaemic or haemorrhagic infarcts, and solitary or multiple abscesses were the predominant neuropathological findings. The lungs were the probable portal of entry; however, isolated CNS aspergillosis was seen in two patients. Antemortem diagnosis of the infection was made in half of the patients. Concomitant diabetes mellitus was noted in $59 \%$ of the patients and bacterial or other severe infections in $86 \%$. No specific clinical or pathological pattern could be identified among patients with different types of organ transplants. In addition CNS aspergillosis was preceded by organ rejection and the need for intense immunosuppression and retransplantation in the majority of the patients.
\end{abstract}

(F Neurol Neurosurg Psychiatry 1993;56:188-193)

Presbyterian

University Hospital, University of Pittsburgh, School of Medicine, Pittsburgh, Pennsylvania, USA

Department of Surgery

J Torre-Cisneros

T E Starzl

R L Simmons

M Martin

Department of

Neurology

O L Lopez

Department of

Medicine

$S$ Kusne

Department of

Pathology

(Neuropathology)

A J Martinez

Correspondence to:

Dr Lopez, 3600 Forbes

Dr Lopez, 3600 Forbes

Avenue, Iroquois Building,

15213, USA

Received 16 November 1991 and in revised form

6 November 1991.

Accepted 30 April 1992
Infection with Aspergillus spp remains an important cause of morbidity and mortality in immunosuppressed organ transplant recipients. ${ }^{1}$ This opportunistic fungal infection commonly involves the CNS and produces devastating neurological sequelae. ${ }^{2-6}$ Its association with other severe infections in transplant patients makes precise antemortem diagnosis difficult, and often results in delayed therapy. ${ }^{2-6}$ Although successful treatment of CNS aspergillosis ${ }^{78}$ has been reported, response to antifungal therapy is generally poor in organ transplant patients. ${ }^{10}$ This study reviews the clinical and neuropathological findings of 22 organ transplant recipients with CNS aspergillosis. Recognition of these features may encourage clinicians to pursue empiric therapy based on clinical suspicion alone.

Material and methods

SUBJECTS

The medical records and necropsy reports of
22 adult subjects with CNS aspergillosis (20 diagnosed by necropsy and two by brain biopsy) who had undergone solid organ transplantation at the University of Pittsburgh Medical Center (UPMC) from January 1981 to December 1990 were reviewed. The subjects were eight men and 14 women ranging in age from 18 to 58 years, [mean (SD) $38 \cdot 1(14 \cdot 3)$ years]. Those diagnosed by necropsy included: 12 patients who had an orthotopic liver transplantation, five patients with kidney transplantations, two with heart transplantations, and one patient with an abdominal cluster transplantation, which involved en-block replacement with liver, pancreas and small bowel. The two diagnosed by biopsy included: one patient with a liver transplantation and another with kidney transplantation. Although both patients died subsequently, necropsy was not performed.

Our patients were selected from among the 218 transplant patients who had complete necropsy carried out at the UPMC from January 1981 to December 1990; this included 112 liver, 19 kidney, 84 heart and 3 cluster transplant patients. Of 4448 patients who had organ transplantation at the UPMC during that time, 2180 had liver, 1714 kidney, 538 heart and 16 had cluster transplants.

\section{Methods}

The clinical records were reviewed by an internist (JTC) and a neurologist (OL) in each case to identify and characterise the neurological events. Clinical parameters recorded included any alteration of the mental status, seizures, focal neurological symptoms and meningism. Mental status alteration was considered to be rapidly progressive when it evolved within 24 hours and progressive when it evolved over 24 hours. CT scans of the head, EEGs, laboratory and other specific neuroradiological reports were reviewed when pertinent.

Standard immunosuppressive protocols consisting of Cyclosporin A (CyA) and prednisone have been published previously. ${ }^{11-14}$ Serum levels of CyA were determined routinely, with therapeutic level ranging from 600 to $1000 \mathrm{ng} / \mathrm{ml}$. Azathioprine was frequently used in combination with CyA and prednisone. Rejection episodes were managed with methylprednisolone as 1 gram intravenous bolus or 1 gram daily for 5 days. A monoclonal anti-lymphocyte globulin (OKT3) was occasionally used to treat steroid resistant rejection episodes. Rabbit antithymocyte globulin 
(RATG) was administered to one heart transplant patient.

The underlying diagnoses of liver transplant recipients were: a) fulminant hepatitis (three cases); b) Hepatitis B Virus cirrhosis (two cases); c) autoimmune cirrhosis (two cases); d) cirrhosis of unknown aetiology (three cases); e) primary biliary cirrhosis (two cases) and f) Budd-Chiari syndrome (one case). In kidney transplant patients the diagnoses were: a) hypertensive nephropathy (three cases); b) polycystic kidney disease (one case); c) systemic lupus erythematosus nephropathy (one case) and d) chronic renal failure of unknown aetiology (one case). In heart transplant patients the diagnoses were: a) atherosclerotic heart disease (one case) and b) dilated cardiomyopathy (one case).

Neuropathological methods used in transplant recipients and brain biopsy procedures have been described in detail previously. ${ }^{2}{ }^{15-17}$

\section{Results}

\section{NEUROPATHOLOGY}

Table 1 summarises the neuropathological findings in each organ recipient. Macroscopic examination of the CNS showed gross abnormalities in all but one patient $(95 \%)$. The most frequent pattern observed was solitary or multiple areas of haemorrhagic or ischaemic encephalomalacia (figure A). One case of haemorrhagic softening had obvious cavitation. In other cases the macroscopic lesions were single or multiple abscesses. Both patterns were found most frequently in the cerebrum without preference for areas supplied by the anterior or posterior circulation. Cerebellum and brainstem were affected with less frequency, but when it occurred the predominant pattern was a haemorrhagic infarct. Two patients $(10 \%)$ had cerebellar abscesses. Two subjects had subarachnoid haemorrhages, and two others had subdural haematomas. In one patient subarachnoid haemorrhage was associated with a ruptured mycotic aneurysm of the left middle cerebral artery. Uncal herniation from a large cerebral haematoma was noted in one patient. The sole patient without an apparent macroscopic lesion showed multiple microabscesses.

Microscopically, the most frequent findings were ischaemic and haemorrhagic infarcts, probably due to arteritis and arteriolitis with fungal thrombosis and obliteration of the vessel lumen (figure B), in 15 patients (75\%). In some areas the thrombosed hyphae penetrated the blood vessel walls into the adjacent oedematous cerebral parenchyma, producing a diffuse pattern of multifocal haemorrhagic infarcts. Aspergillus invasion of the wall of large blood vessels causing a mycotic aneurysm was observed in one patient.

Cerebral and cerebellar abscesses composed of necrotic CNS parenchyma with minimal acute and chronic inflammatory reaction and the presence of hyphae were observed in three patients $(15 \%)$ at necropsy (figure C), and in

Table Clinicopathological correlations with 22 cases of CNS Aspergillosis after organ transplantation

\begin{tabular}{|c|c|c|c|c|c|}
\hline Case & Age/Sex & Focal deficits & Seizures & Alteration of Mental Status & Neuropathological Findings \\
\hline \multicolumn{6}{|c|}{ I Liver Transplant } \\
\hline$\frac{1}{2}$ & $39 / \mathrm{F}$ & - & Grand mal & Progressive & Abscesses; $R$ and $L$ Frontal and $R$ parietal \\
\hline 3 & 40/M & $\overline{-}$ & & $\begin{array}{l}\text { Progressive } \\
\text { Rapidly Progressive }\end{array}$ & $\begin{array}{l}\text { L Occipital abscess (biopsy) } \\
\text { R Frontal and parietal IPH; L Parietal and }\end{array}$ \\
\hline 4 & & $\mathbf{R}$ hemiparesis & & Rapidly Progressive & rebral and midbrain \\
\hline $\begin{array}{l}5 \\
6\end{array}$ & $\begin{array}{l}31 / \mathrm{F} \\
58 / \mathrm{F}\end{array}$ & $\overline{\mathrm{R}}$ hemiparesis & Grand mal & $\begin{array}{l}\text { Rapidly Progressive } \\
\text { Rapidly Progressive }\end{array}$ & $\begin{array}{l}\text { Ischaemic infarcts; Leptomeningeal aspergillosis } \\
\text { Microabcesses; cerebral; cerebellar and } \\
\text { midbrain }\end{array}$ \\
\hline 7 & $18 / \mathrm{F}$ & - & - & Rapidly Progressive & $\mathrm{R}$ occipital, haemorrhagic infarct \\
\hline 8 & $21 / \mathrm{F}$ & - & - & & $\begin{array}{l}\text { L Frontal ischaemic infarct: Leptomeningeal } \\
\text { aspergillosis }\end{array}$ \\
\hline 9 & $36 / \mathrm{F}$ & - & - & Rapidly Progressive & $\begin{array}{l}\text { Haemorrhagic and ischaemic infarcts; cerebral, } \\
\text { cerebellar and brainstem }\end{array}$ \\
\hline 10 & $48 / \mathrm{F}$ & R Hemiparesis & $\begin{array}{l}\text { Grand mal } \\
\text { (status) }\end{array}$ & Progressive & $\begin{array}{l}\text { Ischaemic infarcts; } L \text { Frontal and Parietal; } \\
\text { Abscesses; L Frontal and Occipital, and R } \\
\text { Frontal and cerebellar }\end{array}$ \\
\hline 11 & $24 / F$ & - & Grand mal & Progressive & $\begin{array}{l}\text { Haemorrhagic and ischaemic infarcts; cerebral, } \\
\text { cerebellar and brainstem; CPM; acute } \\
\text { leptomeningitis }\end{array}$ \\
\hline 12 & $20 / \mathrm{M}$ & - & - & Rapidly Progressive & $\begin{array}{l}\text { Haemorrhagic infarcts; cerebral and cerebellar; } \\
\text { CPM }\end{array}$ \\
\hline 13 & $51 / \mathrm{F}$ & - & Grand $\mathrm{mal}$ & ive & $\begin{array}{l}\text { Haemorrhagic and ischaemic infarcts; cerebral } \\
\text { and cerebellar }\end{array}$ \\
\hline \multicolumn{6}{|r|}{ 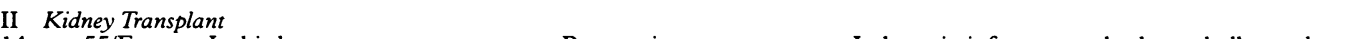 } \\
\hline 14 & $55 / \mathrm{F}$ & \multirow{2}{*}{$\begin{array}{l}\text { L third nerve } \\
\text { palsy }\end{array}$} & - & Progressive & \multirow{3}{*}{$\begin{array}{l}\text { Ischaemic infarcts; cerebral, cerebellar and } \\
\text { midbrain; L SDH } \\
\text { Haemorrhagic infarcts; cerebral, cerebellar and } \\
\text { midbrain } \\
\text { Ischaemic infarcts; cerebral and cerebellar; } L\end{array}$} \\
\hline 15 & $58 / \mathrm{F}$ & & - & Progressive & \\
\hline 16 & $56 / \mathrm{F}$ & Hemianopia & - & - & \\
\hline 17 & $54 / F$ & R Hemiparesis & - & Rapidly Progressive & $\begin{array}{l}\text { Ischaemic infarcts; cerebral, cerebellar and } \\
\text { midbrain; ruptured mycotic aneurysm. LMCA }\end{array}$ \\
\hline 18 & $38 / \mathrm{M}$ & - & Grand mal & Rapidly Progressive & $\begin{array}{l}\text { Haemorrhagic infarts; cerebral, cerebellar and } \\
\text { midbrain; Acute leptomeningitis }\end{array}$ \\
\hline 19 & $38 / M$ & - & - & Progressive Alteration & L Temporal abscess, (Biopsy) \\
\hline III & leart Trar & & & & \\
\hline $\begin{array}{l}20 \\
21\end{array}$ & $\begin{array}{l}51 / M \\
16 / M\end{array}$ & $\underline{\mathrm{R}}$ Hemiparesis & $\begin{array}{l}\text { Grand mal } \\
\text { Grand mal }\end{array}$ & $\begin{array}{l}\text { Progressive } \\
\text { Progressive }\end{array}$ & $\begin{array}{l}\text { Abscesses; L Frontal and Temporal } \\
\text { Ischaemic and haemorrhagic infarcts; } L \\
\text { occipital and parietal }\end{array}$ \\
\hline $\begin{array}{l}\text { IV } \\
22\end{array}$ & $\begin{array}{l}\text { luster } \operatorname{Tr} \\
32 / \mathrm{F}\end{array}$ & & - & - & $\begin{array}{l}\text { Haemorrhagic and ischaemic infarcts; cerebral, } \\
\text { cerebellar and midbrain; bilateral; SAH }\end{array}$ \\
\hline
\end{tabular}

R: right; L: Left; IPH: Intraparenchymatous haemorrhage; CPM: Central pontine myelinolysis; SDH: Subdural haematoma; SAH: Subarachnoid haematoma; LMCA: Left middle cerebral artery. 
Figure A) Coronal section of the cerebral hemispheres at the level of the frontal lobes, showing two large areas of haemorrhagic

encephalomalacia on the right side and two small foci on each cingulate gyrus; B) Thrombosed middle-sized blood-vessel showing branched hyphae within the thrombus, penetrating the arterial wall (Grocott's Methenamine-Silver, $250 \times$ ); C) Abundant purulent exudate containing clusters of branched septated hyphae (Haematoxilin $\mathcal{E}$ Eosin, $250 \times$ ); D) Patient 2 in table 1; axial CT-scan with contrast shows a solitary brain abscess in the left occipital lobe.
A

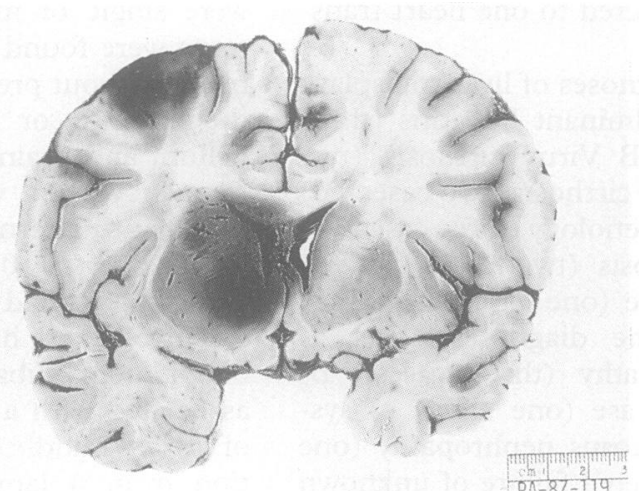

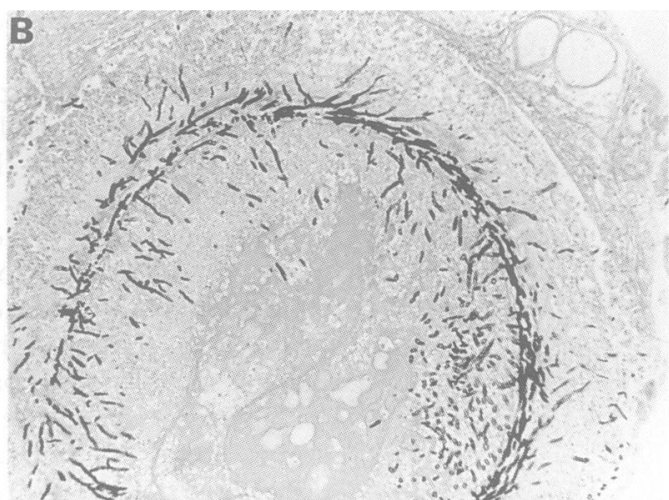

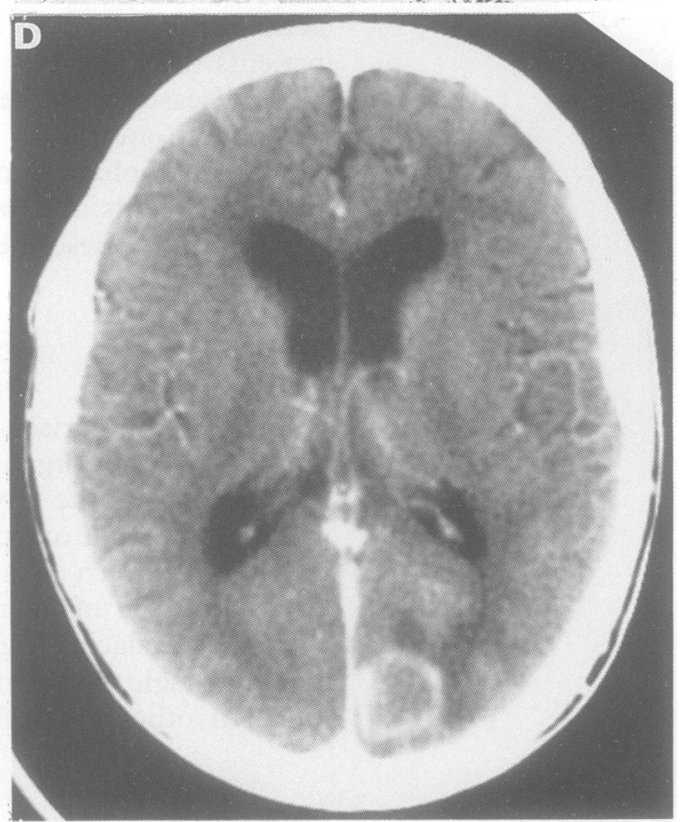

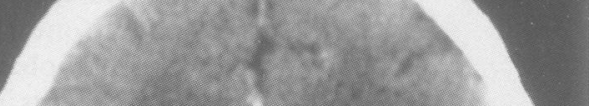
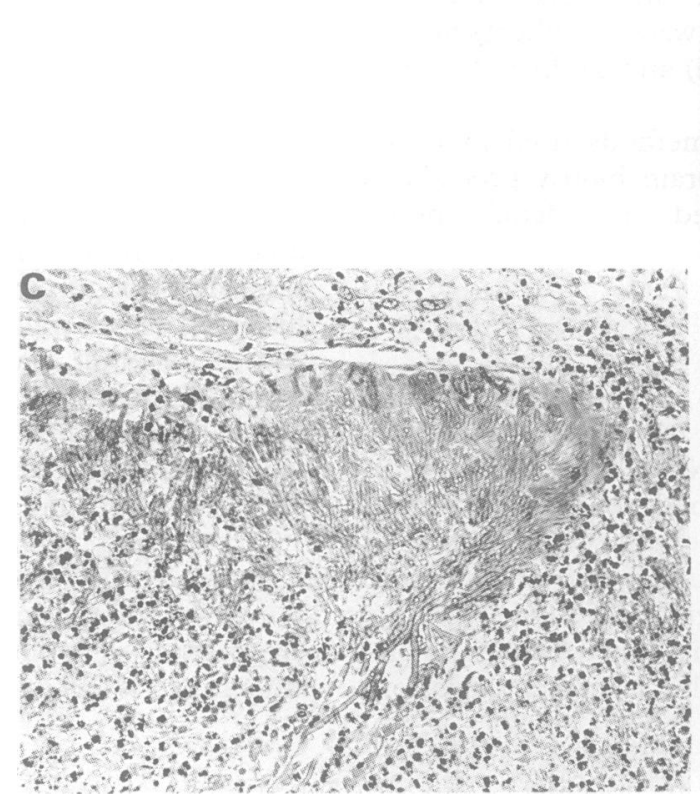

two patients with solitary abscesses diagnosed antemortem by brain biopsy (figure D). Aspergillus infection of the leptomeninges, accompanied by subacute and chronic inflammation was noted in two patients (10\%). Both cases were associated with necrotising lesions in the cerebral cortex involving both grey and white matter.

In 18 of 20 patients at necropsy, the most common portal of entry was the lung. One patient had concomitant aspergillus infection of both lungs and middle ear. Aspergillus spp pneumonia was characterised by hyphal infiltration, angioinvasion and necrotising polymorphonuclear infiltrates. The portal of entry in one liver transplant patient and one cluster transplant patient was not identified.

Disseminated aspergillosis involving the CNS, lungs and at least one other organ was observed in 11 patients $(55 \%)$. Infection restricted to CNS and lungs developed in seven patients (35\%) and isolated CNS aspergillosis was present in two patients $(10 \%)$. The histological pattern of inflammation was similar in all organs examined. The cause of death in the 20 necropsy cases was multi-organ failure secondary to sepsis.

Of 17 patients $(77 \%)$ with positive cultures, Aspergillus fumigatus was noted in $13(76 \%)$ and Aspergillus flavus in four (24\%).

\section{Clinical neurological features}

The table summarises the clinical profile of each patient and correlates them with the neuropathological findings. Neurological complications were observed in 21 patients (95\%). The most common clinical finding was alteration of mental status in 19 patients (82\%), which was rapidly progressive in nine patients $(41 \%)$ and progressive in nine $(41 \%)$.

Focal neurological symptoms were noted in seven patients $(32 \%)$. Hemiparesis was seen in five patients, and was invariably caused by CNS structural lesions manifested by abscesses or haemorrhagic or ischaemic infarcts in the contralateral neocortex and subcortical white matter. One patient with small left parietal and occipital infarcts had hemianopia. Ipsilateral left third cranial nerve palsy, probably due to increased intracranial pressure with nerve compression, was observed in a patient with a left lateral frontal subarachnoid haemorrhage. No lesion was found in third nerve or Edinger-Westphal nuclei. Seizures were observed in nine patients ( $41 \%)$; eight patients had grand mal, one myoclonus and one patient with grand mal was in status epilepticus.

Meningism was noted in four patients $(18 \%)$. It was related to aspergillus leptomeningitis in one case and to subarachnoid haemorrhage secondary to the rupture of a 
mycotic aneurysm in another case. The remaining two subjects with meningism had acute purulent leptomeningitis due to Pseudomona aeruginosa. The infections were concomitant with CNS aspergillosis.

Headaches were observed in six patients $(27 \%)$, four with meningism as described above and the other two with cerebral infarcts, one of whom developed subarachnoid haemorrhage. The only patient without clinical symptoms had a focal aspergillosis of adenohypophysis, bilateral subarachnoid haemorrhage and multiple haemorrhages throughout the cerebral hemispheres.

Although 20 subjects proved to have lung involvement at necropsy, antemortem diagnosis was made in only 11 patients $(50 \%)$. These patients were treated with Amphotericin $B$ without clinical response. In the other nine cases, pulmonary infiltrates consistent with bronchopneumonia were unknowingly managed as a bacterial pneumonia.

The survival time after transplantation ranged from 13 to 2705 days [mean (SD): $238 \cdot 2(568 \cdot 8)$ days; median 65 days]. The time of occurrence of CNS aspergillosis varied from seven to 2555 days after the transplant [mean (SD): 221 (540.7) days; median 41 days]. The most critical period for development CNS aspergillosis was the initial two months after transplantation, as noted in 14 patients (64\%). Liver transplant patients represented nine of these 14 cases, and six of the nine cases occurred in the first month. There were four cases occurring after the first year, and three were liver transplants. Only one liver transplant patient developed CNS aspergillosis between the second month and one year after transplant. Of the six cases after kidney transplant, four cases occurred in the second and third month. Aspergillosis occurred in a constant rate throughout the year. Twelve episodes occurred between November and April and 10 between May and October. The duration of surgery ranged from 10-38 hours [mean (SD): $22(9 \cdot 6)$ hours] and in 12 cases (92\%) was more than 12 hours.

CNS aspergillosis was observed following intense anti-rejection therapy in 18 patients $(82 \%)$. Nine patients $(41 \%)$ were treated with antilymphocyte globulin, nine $(41 \%)$ with boluses of steroids and $14(64 \%)$ with recycles of steroids. Rabbit anti-thymocyte globulin was administered to one patient (4\%). Combined antirejection therapy with two or more of these agents was used in 12 patients (54\%). Eleven patients had more than one transplant $(50 \%)$. They were 10 of 13 liver transplant patients $(77 \%)$ and one of six kidney transplant patients $(17 \%)$.

CNS aspergillosis was associated with at least one systemic infection in 19 patients $(86 \%)$ and with multiple infections in 11 $(50 \%)$ of those patients. Systemic infections included: cytomegalovirus (CMV) disease (seven cases), peritonitis (eight cases), sepsis of unknown origin (five cases), pneumonia (three cases), hepatitis B virus (two cases), systemic candidiasis (one case), herpes simplex virus (HSV) disease (one case), human immunode- ficiency virus (HIV) infection (one case) and otitis media (one case). The last patient developed an acute purulent meningitis secondary to the ear infection which was concurrent with the CNS aspergillosis.

All but one patient received additional intravenous antibiotics two months before the infection. The duration of the treatment with antibiotics ranged from five to 70 days [mean (SD): $19 \cdot 6$ (19.7) days].

Cerebral haemorrhagic events in the presence of coagulopathy were observed in 11 patients, while six patients had coagulopathy without haemorrhages. Uncontrolled diabetes was found in 13 patients $(59 \%)$ and nine had received liver grafts.

\section{Discussion}

This retrospective study of 22 organ transplant patients with CNS aspergillosis indicates that the most common neurological symptoms were alteration of mental status, seizures and focal motor deficits. The main neuropathological finding was fungal invasion of the wall of the cerebral blood vessel with thrombosis and subsequent ischaemic or haemorrhagic infarcts and subdural or subarachnoid haemorrhages. No specific clinical or pathological pattern of the infection could be observed among patients with different types of organ transplantation.

Organ transplant recipients are at risk of systemic and CNS aspergillosis. Estimates of frequency of aspergillosis after organ transplant have varied from $1-10 \%,{ }^{1018} 19$ with CNS involvement in $10-50 \%$ of those patients. $^{20-22}$ In this study, approximately $9 \%$ of the 218 patients where necropsy was carried out had aspergillosis. The infection was observed in $11 \%$ of liver transplant, $26 \%$ of kidney transplant and $2 \%$ of heart transplant patients. Although aspergillosis seemed to be more frequent in kidney transplant patients, these figures represent only patients in whom necropsy was performed, consequently they may overestimate the actual rate of CNS aspergillosis.

The most important clinical symptom observed in these patients was alteration of mental status. Whether these findings were a direct consequence of CNS aspergillosis or due to the frequent metabolic abnormalities seen in these patients was difficult to evaluate. In addition, these patients had other risk factors directly related to the transplant process. Primary organ dysfunction exerts an important effect on mental status, and encephalopathy and coma are not uncommon findings in patients under immunosuppressive therapy. ${ }^{23}$ It is likely that a combination of these factors had important deleterious effects on the mental status of these patients.

Likewise, seizures are a common neurological complication in organ transplantation. Consistent with previous reports, multiple metabolic abnormalities and CNS structural lesions were major factors contributing to the onset of seizures in most patients. ${ }^{15} 25$ High blood levels or normal levels of CyA could have enhanced the risk of seizures in these 
patients. $^{2627}$ However, CNS structural lesions such as abscesses, haemorrhages and infarcts played an important role in the onset of seizures in this series.

Focal motor deficits were also common and were often associated with vascular lesions or abscesses. The predilection of Aspergillus spp for invasion of blood vessel walls with subsequent thrombosis, infarcts and haemorrhages explain, in part, the focal motor deficits. This tendency to invade blood vessels has been described previously, ${ }^{4}$ including the uncommon finding of ruptured Aspergillus mycotic aneurysms. In addition, coagulopathy is another common occurrence in transplant patients (for example, liver transplant), ${ }^{28}$ and was seen in $77 \%$ of patients in this series. Thus the combination of fungal invasion of cerebral blood vessels and coagulopathy were the probable mechanism of cerebral bleeding and the underlying cause of focal motor deficits in these patients.

Meningeal signs such as headaches, Brudzinski's sign and Kernig's sign were uncommon, occurring in four patients. They were related to Aspergillus spp leptomeningitis in one case, bacterial leptomeningitis in two cases, and to subarachnoid haemorrhage secondary to a rupture mycotic aneurysm in another case. The paucity of meningeal signs in this study could be explained by the tendency of the fungus to invade subcortical vessels. ${ }^{4}$

Aspergillus spp are primary respiratory pathogens, and the lungs are the main portal of entry of disseminated infection. ${ }^{1}$ In contrast to previous reports of $\mathrm{CNS}$ aspergillosis originating in the lungs, ${ }^{5}$ we were unable to identify the source of infection in two patients. In immunocompromised patients other sources such as skin and paranasal sinuses should be considered. ${ }^{1}$ No patient demonstrated skin abnormalities in this series, however, sinus examination was not specifically addressed at necropsy in most of these patients.

The majority of CNS aspergillosis occurred within the first three months after organ transplantation which is the most critical period for severe infection in general. ${ }^{29}{ }^{30}$ Liver transplant patients had earlier onset of symptoms compared with other transplant recipients. A second peak of incidence was observed after the first year and was associated with chronic rejection and/or retransplantation during a period of intense immunosuppression. In addition, we did not find the seasonal incidence reported in previous studies. ${ }^{5}$

The concomitant presence of other fungal, viral or bacterial infections often precludes a clear diagnosis of CNS aspergillosis in immunosuppressed organ recipients. ${ }^{145}$ Thus the identification of a characteristic clinical profile in which this infection occurs is critical. CNS aspergillosis was frequently preceded by organ rejection, retransplantation and aggressive anti-rejection therapy. ${ }^{5}$ Although steroids have been noted to be a major predisposing factor, ${ }^{31}$ these data indicate that $\mathrm{CyA}$, monoclonal anti-lymphocyte globulin (OKT-3) and rabbit anti-thymocyte globulin, individually or in combination, exert an important influence in the development of this fungal infection. This finding is consistent with recent observations on transplant patients that found the use of antirejection therapy, especially monoclonal antilymphocyte globulin (OKT-3) on transplant patients associated with aspergillosis and CMV infection..$^{31-33}$ Intravenous antibiotics ${ }^{34}$ and diabetes mellitus ${ }^{35}$ also facilitate the proliferation and dissemination of the fungus. Interestingly, despite the presence of diabetes in $59 \%$ of our patients, we did not observe other fungal infections, usually associated with this metabolic condition (for example, mucormycosis, candidiasis).

The prognosis for organ transplant patients with CNS aspergillosis is very poor, even with appropriate treatment. ${ }^{9}$ Among the possible reasons for this unfavourable prognosis is the fact that this infection is often diagnosed late or incorrectly. In 11 of the 20 patients who had necropsies, the clinical diagnosis was made antemortem. In the remaining nine, the diagnosis of aspergillosis was not made until necropsy. Torres-Cisneros et $a l^{33}$ recently examined the charts of 2180 liver transplant patients and found that 39 developed aspergillosis. Twenty nine of these patients had invasive aspergillus lung infection; however, aspergillus respiratory cultures were positive early in the course of infection in only $23 / 29$ patients. In addition, $92 \%$ of these patients died, and all patients with CNS Aspergillus infection died.

We cannot overemphasise the critical need for aggressive evaluation of immunosuppressed patients, and for early diagnosis of systemic aspergillosis before it disseminates to the CNS. Whether clinicians should institute antifungal therapy based on clinical suspicion alone is a major problem in the management of this infection. This decision has to be taken on an individual basis, and our findings may help clinicians involved in such a situation. Finally, we hope that the introduction of newer antifungal agents (for example, liposomal amphotericin, itraconazol) will improve the efficacy of treatment for these patients.

Dr Torre-Cisneros is a Visiting Fellow at the University of Pittsburgh, School of Medicine from the Reina Sofia Hospital, University of Cordoba School of Medicine. Dr Torre-Cisnero is supported by the $90 / 5285$ grant of the Fondo de Investigaciones Sanitarias (FIS) of Spain. Ms Deborah Pulkowski helped in the preparation of the manuscript.

1 Bodey GP, Vartivarian S. Aspergillosis. Eur f Microbiol Infect Dis $1989 ; 8: 413-37$.

2 Martinez AJ, Estol C, Faris AA. Neurologic complications of liver transplantation. Neurol Clin 1988;6:327-48.

3 Martinez AJ, Puglia J. The neuropathology of liver, hear and heart-lung transplantation. Transplant Proc 1988;20 (suppl 1):806-9.

4 Walsh TJ, Hier DB, Caplan LR. Aspergillosis of the central nervous system: clinicopathological analysis of 17 patients. Ann Neurol 1985:18:574-82

5 Boon AP, Adams DH, Buckels J, McMaster P. Cerebral aspergillosis in liver transplantation. $\mathcal{F}$ Clin Pathol 1990 43:114-8.

6 Beal MF, O'Carroll CP, Kleinman GM, Grossman RI Aspergillosis of the nervous system. Neurology 1982;32:
473-9.

7 Conen PE, Walker GR, Turner JA, Field P. Invasive primary aspergillosis of the lung with cerebral metastasis and complete recovery. Dis Chest 1962;42:88-94.

8 Burton JR, Zachery JB, Bessin R. Aspergillosis in four renal transplant recipients. Diagnosis and effective treatment with amphotericin B. Ann Intern Med 1972;77:383-8.

9 with amphotericin B. Ann Intern Med 1972;77:383-8. ment of invasive aspergillosis. Review of 2121 published ment of invasive aspergillosis. Review of
cases. Rev Infect Dis 1990;12:1147-1201.

10 Weiland D, Ferguson RM, Peterson PK, Snover DC, 
Simmons RL, Najarian JS. Aspergillosis in 25 renal transplant patients. Epidemiology, clinical presentation, diagnosis and management. Ann Surg 1983;198:622-9.

11 Starzl TE, Klintmalm GBG, Weil R, Porter K, et al. Cyclosporin $A$ and steroid therapy in sixty-six cadaver kidney recipients. Surg Gynecol Obstet 1981;153:486-94.

12 Starzl TE, Klintmalm GBG, Porter KA, Schroter GP. Liver transplantation with the use of cyclosporin $\mathrm{A}$ and prednisone. $N$ Engl 7 Med 1981;305:266-9.

13 Griffith BP, Hardests RL, Bahson HT. Powerful but limited immunosuppression for cardiac transplantation with cyclosporin and low-dose steroids. F Thor Card Surg 1984;87:35-42.

14 Starzl TE, Rowe MI, Todo S, Jaffe R, et al. Transplantation of multiple abdominal viscera. $\mathcal{F} A M A$ 1989;261:

15 Estol CJ, Lopez O, Brenner RP, Martinez AJ. Seizures after liver transplantation: a clinicopathologic study. Neurology

16 Montero CG, Martinez AJ. Neuropathology of heart transplantation: 23 cases. Neurology 1986;36:1149-54.

17 Hall WA, Martinez AJ, Dummer S, Griffith BP. Central nervous system infections in heart and heart-lung transplantation. Arch Neurol 1989;46:173-7.

18 Peterson PK, Balfour HH, Fryd DS, Ferguson RM, Simmons RL. Fever in renal transplant recipients: causes, prognostic significance and changing patterns at the University of Minnesota Hospital. Am f Med 1981; 71:345-51.

19 Britt RH, Enzmann DR, Remington JS. Intracranial infections in cardiac transplant recipients. Ann Neurol tions in cardiac transplant recipients. Ann Neurol

20 Conti DJ, Rubin RH. Infection of the central nervous system in organ transplant recipients. Neurol Clin 1988;6:241-60.

21 Kaplan K. Brain abscess. Med Clin 1985;69:345-60.

2 Gustafson TL, Schaffner W, Lavely GB, Straton CW. Invasive aspergillosis in renal transplant recipients: correlations with corticosteroid therapy. F Infect Dis 1968; 148: $230-8$.

23 Plum F, Hindfelt B. The neurological complications of liver disease. In: Vinken DJ, Bruyn GW, eds. Handbook of clinical neurology: Amsterdam, North Holland, 1976;
349-77.

24 Lane RJM, Roche SW, Leung AA, Greco A, Lance L. Cyclosporin neurotoxicity in cardiac transplant recipients. $\mathcal{F}$ Neurol Neurosurg Psychiatry 1988;51:1434-7. 25 Grigg MM, Costanzo-Nordin MR, Celesia GG, Kelly MA,
Silver MA, Sobotka PA, Robinson JA. The etiology of seizures following cardiac transplantation. Transplant Proc 1988;20 (suppl 3):937-44.

26 O'Conner JP, Kleiman DS, Kunze HE. Hypomagnesemia and cyclosporin toxicity. Lancet $1985 ; 1: 103-5$.

27 Boogaerts MA, Zachee P, Verwilghen RL. Cyclosporin, methyl-prednisolone and convulsions. Lancet 1982;2: methyl-pred

28 Estol CJ, Pessin MS, Martinez AJ. Cerebrovascular complications after orthotopic liver transplantation: a clinicopathological study. Neurology 1991;41:815-9.

29 Kusne S, Dummer JS, Singh N, Iwazuki S, et al. Infections after liver transplantation: an analysis of 101 consecutive cases. Medicine 1988;67:132-43.

30 Zeluff BJ. Fungal pneumonia in transplant recipients. Sem Resp Infect 1990;5:80-9.

31 Singh N, Dummer S, Kusne S, Breinig MK, et al. Infections with cytomegalovirus and other herpes viruses in 121 liver transplant recipients: transmission by donated organ and the effect of OKT3 antibodies. F Infect Dis 1978; 158:124-31.

32 Singh N, Dummer JS, Kusne S, Makown L, StarzlT, Ho M Impact of OKT3 therapy on cytomegalovirus and Herpes Simplex virus infections after liver transplantation. Transplant Proc 1988;20(Suppl1):661-2.

33 Torres-Cisneros J, Kusne S, Martin M, Manez R, Simmons RL, Starzl T. Aspergillosis: colonisation versus invasive
. Ans disease in liver transplant patients. Abstracts from the 31 st Interscience Conference on Antimicrobial Agents and Chemotherapy. Chicago, Illinois, 1991;221.

34 Seeling MS. Mechanisms by which antibiotics increase the incidence and severity of candidiasis and alter the immunologic defenses. Bacteriol Rev 1966;30:442.

35 MacCuish AC, Urbaniak SJ, Campbell CJ, Duncan LJP, Irvine WJ. Phytohemagglutinin transformation and circulating lymphocyte subpopulation in insulin-dependent diabetics patients. Diabetes 1974;23:708-12. 